relaxation of the tone and amplitude. This effect showed itself within five minutes and progressed until the heart stopped. After perfusing with Ringer's solution there was recovery of the amplitude, but the pulse-rate remained depressed. A concentration of $1: 8,000$ of the substance did not affect the contraction of the heart.

The growth of tissue cultures from rabbit testicle ${ }^{4}$ was hindered by raphanin even at a considerable dilution. A concentration of $1: 20,000$ of the antibiotic prevented entirely the growth of the explants, and a dilution of $1: 40,000$ caused diminished growth of the fibroblasts, as compared to that of the controls.

We are indebted to Prof. V. Bruckner and Dr. J. Kovécs for carrying out the elementary analyses.

Full details of these observations will be published elsewhere.

George Ivánovics STEPHAN HORVÁTH

Institute for General Pathology and Bacteriology,

University of Szeged, Hungary May 28.

1 Jacobs, W. A., and Hoffman, A., J. Biol. Chem., 67, 333 (1926). Köckemann, A., Ber, deut. bot. Ges., 52, 523 (1934).

'Kuhn, R., Jcrehel, D., Moewus, F., Möller, E. F., and Lettré, H., Naturwiss., 31, 468 (1934)

4 Ivánovies, G., and Hyde, R. R., Amer. J. Hyg., 23, 55 (1930).

\section{Thiamine of Milled Raw and Parboiled Rice}

IT has long been known that the vitamins of cereals are not evenly distributed throughout the grain but are concentrated mainly in the outer coats and in the germ, which consists of the embryo and attached scutellum.

Analyses of the meals and flours of the miller have been somewhat misleading because some mixing of the products from different parts of the grain takes place within the mills. Dr. J. J. C. Hinton, of the Cereals Research Station at St. Albans, dissected cereal grains, accurately separating the different structures, and determined the vitamin content of each structure. He reported ${ }^{1}$ that there was a surprising concentration of thiamine in the scutellum of wheat, and that although it forms on an average only 1.54 per cent of the grain, yet it contains 59 per cent of all the thiamine present in the grain. In a later paper ${ }^{2}$ he recorded that the scutellum of rye, maize and barley had similar very high contents of thiamine.

This is an important matter in respect of rice milling, for it is probable that rice is not an exception and that much of the thiamine is concentrated in the scutellum. Rice is either milled raw or it is milled after parboiling. Many analyses have shown that parboiled rice is richer in thiamine than highly milled raw rice, and this agrees with the experience that beriberi is very rare or does not occur where parboiled rice is the staple article of diet.

It has generally been accepted that parboiling distributes the vitamins of the pericarp and germ throughout the whole grain, and therefore milling can remove only a small amount with the bran. Recently, I have examined a large number of grains from several samples of raw milled rice and parboiled rice. The great majority of the grains of raw rice had a concavity marking the site from which the whole germ (scutellum and embryo) had been detached. On the other hand, the grains of par- boiled rice did not show the concavity; but the site of the germ was flattened as though only part of the germ had been removed by milling. It appeared as though parboiling had made the scutellum more adherent, so that it had not been detached during milling.

Hinton ${ }^{2}$ found that twelve hours soaking of wheat did not cause any movement of the water-soluble thiamine to the rest of the grain. He suggested that the cells of the scutellum are not permeable to water until they have been acted upon by acid chloroform or some other agent. Possibly also the high fat content of scutellum may be a bar to the penetration of water.

Parboiling and also the new conversion process, which is parboiling first under vacuum and then under pressure, toughens the rice so that far fewer grains are broken during milling than in the case of raw rice; this lowering of brittleness would help the retention of the scutellum. Probably parboiling does cause some movement of the vitamins within the grain; but its chief value may be the retentiorr of the scutellum.

\section{Lucrus Nicholds}

(Nutrition Adviser)

c/o Special Commissioner in S.E. Asia, Cathay Building, Singapore. May 22.

${ }^{1}$ Hinton, J. J. C., J. Soc. Chem. Ind., London, 61, 143 (1942). ${ }^{2}$ Hinton, J. J. C., Biochem. J., 38, 214 (1944).

\section{Marking Mosquitces with Fluorescent Com- pounds and Watching them by Ultra-Violet Light}

A TECHNYQUE for marking mosquitoes with fluorescent compounds and watching them by ultraviolet light has been developed, to study the move ments of these insects at night without affecting their normal behaviour. The method seems very promising and opens out possibilities for the study of the ecology and bionomies of mosquitoes hitherto not possible.

Zukel $^{1}$ used fluorescent compounds to detect marked insects in a large number of specimens, but no attempt was made to develop the technique to observe the insects at night under natural conditions. For this purpose investigations were carried out to ascertain: $(a)$ the sensitivity of mosquitoes to shorter wave-lengths, $(b)$ whether the insects can take up sufficient dust on their bodies to fluoresce brightly, (c) the toxicity of fluorescent compounds to insects, (d) whether it would be possible to watch the dusted insects at night by ultra-violet light, and what would be the normal range of visibility.

Mosquitoes, unlike some other insects (honey bees and Drosophila), are not sensitive to the ultra-violet radiations of wave-lengths given out by the lamp used (4070-3130 A., $95 \cdot 5$ per cent being concentrated at $3650 \mathrm{~A}$.). Both positive and negative reactions were compared to the behaviour in ordinary light. The species studied were Anopheles maculipennis var. atroparvus, Culex molestus and Aëdes aggypti.

Mosquitoes take up sufficient dust to fluoresce brightly, and the dust does not shake off for a number of days. The fluorescent compounds have apparently no toxic effect on these insects as judged by their survival for more than one and a half months after 